\title{
Ação, elucubração e capitulação: memória e esquecimento em Dom Casmurro
}

\author{
Carla Renata A. S. Gomes*
}

\begin{abstract}
Resumo: Este artigo apresenta algumas reflexões sobre o comportamento político de Capitu a partir das reminiscências de Bento Santiago. A revelação das atitudes políticas da Capitu-menina, através da memória corroída pelo tempo e pela amargura do homem ensimesmado que Bentinho se tornara, recupera ao mesmo tempo aquela ausência de si mesmo denunciada no início da escrita de suas reminiscências diante do fracasso na reprodução da casa de sua infância e na cruel constatação: - "mas falto eu mesmo, e esta lacuna é tudo." Assim, na tentativa de compreender o significado desta lacuna, que em última instância significa compreender o significado da vida vivida, Bento Santiago, agora convertido em Dom Casmurro, empreende pela escrita a reconstituição dos tempos de sua juventude e tenta reviver através da memória o que viveu.
\end{abstract}

Palavras-chave: Machado de Assis; Memória; Esquecimento; Crítica Literária.

\begin{abstract}
This article presents some considerations on Capitu's political orientations based on Bento Santiago's memories. The disclosure of the political attitudes of young Capitu through old memories and the bitterness of a lonely men as Bentinho, recovers the self-absence found in the beginning of the writing of his memoirs facing the failure in depicting his house when he was a child, and in the cruel finding: - "but I myself am lacking, and this lack is everything." Thus, in an attempt to understand the meaning of that lack, which utterly means understanding the meaning of life fully experienced, Bento Santiago, now converted into Dom Casmurro, attempts to depict his youth by means of his writings, and tries to live again through his memoirs.
\end{abstract}

Keywords: Machado de Assis; Memory; Oblivion; Literary Criticism.

Se, conforme um antigo provérbio, "Deus (ou será o Diabo?) está nos detalhes", qualquer obra machadiana constitui um desafio à análise minuciosa. Tal procedimento por mais exaustivo, ingrato e imperfeito, é o necessário tributo, senão a devida homenagem, que prestamos ao escritor que preferia, conforme aludiu em uma de suas crônicas ${ }^{1}$, "catar o mínimo e o escondido" da sociedade brasileira de seu tempo.

O romance Dom Casmurro é uma dessas obras que oferece múltiplas possibilidades de abordagem crítica. É possível analisá-lo sob a ótica da dominação de classes ao modo de Chalhoub, ou como inserido no contexto amplo da categoria de "Romance de Adultério da Mulher Casada" conforme demonstrado por Haberly, ou ainda concentrar-se no jogo narrativo estabelecido entre o claro e o escuro, ou entre verossimilhança e verdade como sugeriu

\footnotetext{
* Doutoranda em Teoria da História e Historiografia na Universidade Federal do Rio Grande do Sul - UFRGS. Na qual desenvolve pesquisa em periódicos literários rio-grandenses do século XIX sob a orientação do Prof. Temístocles Cézar.
} 
Macedo, entre tantas outras que poderiam ser destacadas. Ainda assim, o texto machadiano continua sendo um grande desafio interpretativo.

Recentemente, em artigo publicado na Folha de São Paulo, Eduardo Giannetti (2008), destacava o alto poder de sedução do texto de Machado de Assis, pois "Dom Casmurro se oferece ao nosso deleite, enfeitiça-nos com sua arte, bule com a nossa intimidade, mas jamais se deixa possuir inteiramente". A asserção de Giannetti faz relembrar a "arte fina de Capitu" $(\mathrm{XV})^{2}$, que nos conduz ao demoníaco detalhe da voragem de seus dos olhos — "daqueles olhos que o diabo lhe deu" (XXV). E o poder conferido aos olhos de Capitu, pela memória afetiva perturbada pelo ciúme de Bento Santiago, pode também ser compreendido sob uma outra conotação correspondente à sedução, ou seja, a "arte fina" que movia as ações de Capitu, segundo a percepção de Bentinho, equivaleria a uma atitude política.

Capitu, portanto, na memória ciumenta de Bento, era uma mulher política no sentido de que suas idéias revelavam-se na prática "hábeis, sinuosas, surdas, e alcançavam o fim proposto, não de salto, mas aos saltinhos" (XVIII).

Tal "arte fina” ou política também foi indicada por Merquior como fator central da ficção machadiana (cf. MACEDO, 2005, p.106), o que se traduz por movimentos controlados que possam garantir o acesso de uma "menina que não tem vintém” (XVIII) ao convívio, quiçá permanente, numa família de estrato social superior. A política aqui é então entendida como a "arte do diálogo" e da "sobrevivência" (CHALHOUB, 1998, p.99) numa sociedade em que a vontade senhorial não deve ser jamais contrariada.

A revelação das atitudes políticas da Capitu-menina, através da memória corroída pelo tempo e pela amargura do homem ensimesmado que Bentinho se tornara, recupera ao mesmo tempo aquela ausência de si mesmo denunciada no início da escrita de suas reminiscências diante do fracasso na reprodução da casa de sua infância e na cruel constatação: - "mas falto eu mesmo, e esta lacuna é tudo" (II).

Assim, na tentativa de compreender o significado desta lacuna, que em última instância significa compreender o significado da vida vivida, Bento Santiago, agora convertido em Dom Casmurro, empreende pela escrita a reconstituição dos tempos de sua juventude e tenta reviver através da memória o que viveu. Conforme destaca Macedo:

Ao pretender "atar as duas pontas da vida", Bento Santiago começara por mandar reproduzir noutro lugar a casa que havia mandado demolir porque, como explica, a original já não o

\footnotetext{
${ }^{1}$ MACHADO DE ASSIS. A Semana (1895-1900). $3^{\circ}$ vol. Rio de Janeiro: W. M. Jackson, 1944, p.449.

2 MACHADO DE ASSIS. Dom Casmurro. Todas as citações em números romanos entre parênteses referem-se aos capítulos do romance Dom Casmurro em qualquer edição.
} 
reconhecia, tudo nela lhe era "estranho e adveso". Esse tudo que já não o reconhecia, que lhe era estranho e adverso, era a própria vida decorrida entre as duas pontas que agora, na escrita do livro, pretende atar. (MACEDO, 2005, p.96)

Giannetti ressalta que "bem lido, Dom Casmurro vale por um tratado de psicologia moral”, e Merquior, ao comentar a interpretação de Faoro sobre a obra machadiana em geral, concorda que "o romance machadiano tem como característica tratar do mundo moral, discutir os seus valores" (MERQUIOR, 1998, p.129).

As características e os valores morais da sociedade em que Bentinho fora criado e educado são significativamente enunciados pela voz (e a pena) de Capitu (Machado de Assis), no episódio (XVIII) da ida para o Seminário e na maneira como Capitu instrui Bentinho a agir com o agregado José Dias, conforme destaca Chalhoub:

Capitu precisa primeiro ensinar Bentinho a desempenhar o seu papel, a exercer e ostentar a sua autoridade. "Mostre que quer e que pode", "Dê-lhe a entender que não é favor"; linhas abaixo numa síntese primorosa daquilo que devia caracterizar o exercício "natural" da vontade senhorial, Capitu insiste com Bentinho para que fale a José Dias "com boa cara, mas assim como quem pede um copo de água a pessoa que tem obrigação de o trazer”. (CHALHOUB, 1998, p.120)

Entretanto, Bentinho revela-se inapto às atitudes sugeridas por Capitu. Sua fraqueza moral, aliada à falta de obstinação, não só para impor a sua vontade, mas para sabê-la realmente, é explicitada sempre sob o véu da ingenuidade de Bento-menino.

Assim, enquanto Capitu concentrava-se no problema da ida para o Seminário, Bentinho limitava-se a comer cocadas e observá-la, e o velho Bento exime-se de um julgamento a este respeito, afinal tal atitude poderia "tanto ser perfeição como imperfeição, mas o momento não é para definições tais" (XVIII).

Mas as definições sobre as atitudes morais de Bentinho vêm espalhadas pelo texto como fino tempero machadiano, pois, enquanto Capitu-menina é considerada ardilosa (dissimulada) na condução de seus intentos, Bentinho-Casmurro camufla sua inércia e pouca vontade na resolução dos próprios problemas, ao colocá-los nas mãos divinas por promessas de rezas nunca cumpridas ou nas alternativas cansativas de seu cumprimento, afinal, "Era muito duro subir uma ladeira de joelhos" que poderiam ferir-se; “A Terra Santa ficava muito longe" para uma peregrinação e "As missas [que] eram muito numerosas" seriam um compromisso muito longo... (XX)

Adiante (XXV) no diálogo com o agregado José Dias, Bentinho-Casmurro define-se "tímido" em oposição a "destemido", entretanto, a questão não era somente do enfrentamento aberto da mentira do agregado, mas da revelação de que andava ouvindo atrás das portas, isto 
é através do mascaramento de um dilema moral constrói a falsa idéia da ingenuidade de sua "resistência franca" (XVIII) em oposição aos ardis calculados de Capitu?

Outras indicações de um comportamento apenas pueril do "inocente" menino surgem na narrativa. Primeiro, ao passar pelo portão do Passeio Público, "tira dois vinténs do bolso" para dá-los a um mendigo, enquanto pensa em Capitu e no Seminário, e pede-lhe que rogue a Deus por ele, "a fim de que pudesse satisfazer todos os desejos" sem esquecer de revelar seu nome (XXVII).

Em seguida, na procissão do Santíssimo (XXX), da qual participa constrangido e a contragosto guiado pela vontade de José Dias, não só presencia a disputa entre o agregado e Pádua, pai de Capitu, pela honra de conduzir uma vara do pálio, como se submete ainda outra vez à vontade daquele ao aceitar contrariado a mesma distinção.

Bento-Casmurro suspende novamente seu julgamento sobre o ato egoísta de Bentomenino em relação ao pai de Capitu e, conivente, justifica o impedimento da generosidade pela interferência de José Dias. Entretanto, ressalta o orgulho do menino que abre um cortejo durante o qual "os fiéis se ajoelhavam" e os rapazes da sua idade o "fitavam cheios de inveja". Enquanto isso, Bento-Casmurro descreve a dor e a humilhação do pai de Capitu, relegado à condução da tocha, "da miserável tocha”.

Nem o menino-senhor, nem o casmurro-escritor quiseram refletir sobre a mesquinhez da atitude do pequeno-senhor sem vontade, sem responsabilidade e sem personalidade própria, que apenas e tão somente deixou-se levar pelos desejos do agregado que, afinal, lhe foram convenientes.

Porém não escapou ao julgamento de Bento-Casmurro a humilhação "descabida" de Pádua, já que outros, que nem tiveram o "privilégio" de serem substituídos pelo "senhor" Bentinho, conduziam a tocha com honra. O demérito pairou apenas sobre Pádua na reminiscência casmurra.

Nesta, aliás, a perfídia reina absoluta. Não havendo espaço para méritos humanos, a pena irônica de Machado não poupa ninguém. Não existem inocentes.

A premissa básica do texto sobre as lucubrações de Dom Casmurro poderia ser "fiz tudo para arruinar minha vida e culpei a todos ao meu redor por isso, destruí a mulher que amei e ela foi a única culpada por este sentimento. Agora, caro leitor, prove que eu fui o verdadeiro causador de minhas desventuras, porque não existe crime perfeito!”

Tal sarcasmo é o que fez Giannetti pressentir um certo olhar (oblíquo?!) de Machado de Assis sobre os desventurados analistas que tentam captar-lhe as sutilezas, ao declarar que: 


\begin{abstract}
À medida que lia, relia e me preparava para escrever este artigo - santa ousadia! - fui também me dando conta de uma imagem teimosa que volta e meia aflorava em meio ao trabalho: o olhar zombeteiro de Machado de Assis emergindo do fundo das páginas de "Dom Casmurro" e caçoando do meu esforço em devassar os segredos da obra. Não era uma imagem propriamente visual. Era a sensação difusa e semiconsciente de estar sendo observado. De que Machado calculara de algum modo tudo aquilo, armara milimetricamente o jogo, e depois se postara em algum camarote da eternidade para desfrutar do seu engenho e entreter-se às minhas custas. (GIANNETTI, 2008)
\end{abstract}

A sensação de Giannetti deve ser comum a quase todos os que se propõe a tal empresa, pois o efeito desse esforço é sempre a garantia da vitória da esfinge machadiana. Mesmo que a decifremos, sentimo-nos devorados.

Os ardis do casmurro-narrador, que quer apresentar-se inocente ao leitor sabendo-se de antemão culpado por omissão, estão camuflados ao longo do texto em pequenas digressões sobre a imprecisão de sua memória reforçada pela intenção de escrever um livro que lhe "desse a ilusão" (II) de reviver certos momentos e pessoas que hoje não passam de sombras inquietantes, minimizando as saudades, pois "a saudade é isto mesmo; é o passar e repassar das memórias antigas" (XXXIV).

Ao reprisar tais eventos, memória e imaginação entrelaçam o Bento-casmurro e o Bento-menino, para o qual "a imaginação foi a companheira de toda a existência" e fértil, pois "a menor brisa lhe dava um potro" (XL).

As correções na narrativa também servem de apoio à suposta fidelidade do narrador ao que é contado sem desmentir, ao mesmo tempo, um possível equívoco. Assim, quando se refere ao episódio reflexivo de Capitu, Bentinho afirma que ambos olhavam para o ar. Logo em seguida, corrige-se e diz: "Minto; ela olhava para o chão. [...] Mas eu creio que Capitu olhava para dentro de si mesma, enquanto que eu fitava deveras o chão", entretanto, logo no início do parágrafo ressalvava que "há tanto tempo que isto sucedeu que não posso dizer com segurança...” (XLII).

Ao mesmo tempo, porém, o narrador indeciso readquire a segurança, temporariamente ou convenientemente perdida, e adverte o leitor que, embora este tenha impulsos de jogar longe o livro, que não o faça, ao contrário "fio que torne a pegar o livro e que o abra na mesma página, sem crer por isso na veracidade do autor. Todavia, não há nada mais exato" (XLV).

Enquanto, provavelmente, em algum lugar obscuro Machado está às gargalhadas, o narrador continua sua retórica persuasiva quanto à confiabilidade de sua narrativa, ao confessar sua obsessão pela exatidão, embora admita que "há nisto alguma exageração; mas é bom ser enfático, uma ou outra vez" e emenda uma afirmação deveras questionável: "se eu me ativer só à lembrança da sensação, não fico longe da verdade" (L). 
O interessante a ser observado na memória difusa em razão do tempo, ao mesmo tempo que nítida em virtude das sensações revividas, são os esquecimentos ou omissões de detalhes e, sobretudo de julgamento, sobre eventuais circunstâncias que talvez dariam medida dos impulsos pouco castos de Bentinho, os mesmos que em outros momentos atribuíra a Capitu.

Refiro-me ao episódio (LVIII) em que ele observa a queda de uma mulher na rua que deixa entrever aos passantes a meia e as ligas de seda. Tal visão provoca-lhe uma série de pensamentos sobre outras mulheres e suas meias e ligas e talvez até sem meias... Embora o "inocente" Bentinho, rapidamente, justifique que as via com meias, conjectura que do outro modo também era possível. Mas, limita-se a dizer que suas idéias "eram assim difusas e confusas; [afinal] com certeza não dou nada".

Por outro lado, assevera que "sendo este livro a verdade pura" deve confessar que continuou a ver mulheres, ligas e meias durante toda a noite, e como tudo aquilo continuasse, o estóico Bentinho formulou um tratado entre sua consciência e sua imaginação a fim de que todas aquelas imagens fossem apenas consideradas "como simples encarnações dos vícios" que deveriam ser contemplados "como o melhor modo de temperar o caráter e aguerri-lo para os combates ásperos da vida”.

Nosso glorioso narrador consegue depurar das primeiras manifestações sexuais do jovem Bento toda e qualquer mácula meramente sensualista. Aliás o adolescente Bentinho demonstra mais austeridade moral neste episódio do que em qualquer outro narrado neste livro, afinal, "sábios da escritura, adivinhai o que podia ser. Foi isto".

E a sobriedade da escrita machadiana que não permite excessos nem de certezas, nem de verdades puras ou não, tampouco abriria exceção para a memória. Contudo, num dos poucos momentos auto-reflexivos explicitados no texto, o narrador tão esquivo sobre si mesmo resolve discutir a questão da boa memória, da confusão e da omissão.

Quando Bento-Casmurro afirma que: "Não, não a minha memória não é boa. Ao contrário, é comparável a alguém que tivesse vivido por hospedarias, sem guardar delas nem caras nem nomes, e somente raras circunstâncias" (LIX).

Tal afirmação soa um tanto contraditória para um narrador tão detalhista das ações alheias. Mas ele segue no escrutínio deste comportamento, alegando que mesmo sua cor detestada, isto é, o amarelo, pode ser apenas esquecimento ou confusão. Novamente nosso narrador de si não dá certeza de nada! Entretanto, afirma que prefere o esquecimento à confusão, afinal: "Nada se emenda bem nos livros confusos, mas tudo se pode meter nos livros omissos". 
Aqui o autor de Dom Casmurro retoma uma idéia apresentada anteriormente em Brás Cubas, ou seja, que "o homem [...] é uma errata pensante, [...]. Cada estação da vida é uma edição, que corrige a anterior, e que será corrigida também, até a edição definitiva, que o editor dá de graça aos vermes" (MACHADO DE ASSIS, 1946, cap.XXVII).

Se a premissa formulada em Brás Cubas estiver correta e cada pessoa e sua vida puder ser considerada como um livro, que ao ser reeditado vai corrigindo as edições anteriores. Então a cada estágio da vida, esta deverá aprimorar sua identidade, sua personalidade, através do acúmulo das experiências e também de suas recordações. Portanto, é fundamentalmente a memória guardada sobre nossas escolhas que nos torna responsáveis pelas correções realizadas ou não em cada etapa vivida.

Mas conforme Bento-Casmurro reconhece, sua memória não é de fato boa o bastante, porque apenas guardou raras circunstâncias vividas "comparável a alguém que tivesse vivido por hospedarias" e, além disso, afirma que prefere os livros omissos porque podem ser preenchidos conforme qualquer vontade, em detrimento dos livros confusos que lhe causam aflição.

Então a sensação lacunar de Bento não se refere à transformação de Bento-menino em Bento-Casmurro, mas a efetiva ausência da memória de suas escolhas. Suas lacunas são todas as suas renúncias individuais. São todas as possibilidades irrealizadas de sua vida como a recordação do "soneto que nunca [fez]" (LV). Por fim, são todas as responsabilidades que Bento Santiago colocou nas mãos de outras pessoas para que decidissem por ele, afinal "tudo se acha fora de um livro falho".

É isso que o faz ocupar-se das decisões dos outros, das reflexões dos outros, das responsabilidades que advêm do querer e do agir dos outros e assim ele vai imaginariamente preenchendo as lacunas alheias; enquanto permite ao leitor que preencha as suas, aquelas que ele mesmo não preencheu quando podia.

A reflexão sobre a sua memória é provocada pela necessidade que teve de explicar o quanto um opúsculo de um antigo colega de Seminário "O Panegírico de Santa Mônica" desencadeou nele as lembranças do soneto que não compôs, das fantasias eróticas com meias e ligas, do amigo Escobar que ao menos aparentemente perdeu a vida, mas ganhou a batalha! E mais as lucubrações sobre livros omissos.

No capítulo "A dissimulação" (LXV), Bentinho por duas vezes cala-se e obedece às instruções de Capitu sobre o comportamento a adotar perante a família quanto ao seu futuro sacerdotal e admite estar muito "contente com aquela grande dissimulação de Capitu" e louvando-lhe a astúcia afirma: "Você tem razão, Capitu, [...]; vamos enganar toda esta gente". 
Na seqüência há um breve alerta de que "A vida é cheia de obrigações que a gente cumpre, por mais vontade que tenha de as infringir; deslavadamente". (LXVI) E em seguida (LXVII) confessa que pensou: "Mamãe defunta, acaba o seminário". Escandaliza-se com o próprio pensamento e adverte ao leitor que tal idéia "foi um relâmpago" e "sugestão da luxúria e do egoísmo". Sente remorsos. Pede a Deus que o perdoe. Promete mais orações e escusa-se das antigas não pagas que, afinal, foram prometidas por uma alma cândida e verdadeira, logo, merecedora de confiança.

Mas, os escrúpulos morais de Bento-Casmurro não o impedem de encontrar uma justificativa honrosa não exatamente para tal pensamento, mas pela coragem que demonstra ao confessá-lo publicamente, afinal "poucos teriam ânimo de confessar" tal idéia. Estrategicamente reitera: "eu confessarei tudo o que importar à minha história" e apoiando-se na autoridade de Montaigne cita-o textualmente: "Não são meus gestos que descrevo, sou eu, é minha essência". (LXVIII)

Embora a intenção de descrever sua essência, mencionada explicitamente nesse episódio, soe como parte da retórica persuasiva que compõe a fidedignidade do narrador, considerando que Bento-Casmurro não enfatiza em outras passagens suas próprias falhas, este diálogo com Montaigne possibilita-nos pensar também na luta interior travada na consciência do escritor Bento Santiago entre o "eu como personagem" (Bentinho) e o "eu como autor" (Dom Casmurro) ou ainda o duelo entre a reconstituição da memória sobre o vivido e a revelação do fato vivido.

Refletindo sobre a citação de Montaigne, Bento-Casmurro declara: “Ora, só há um modo de escrever a própria essência, é contá-la toda, o bem e o mal. Tal faço eu, à medida que me vai lembrando e convindo à construção ou reconstrução de mim mesmo" (LXVIII).

O detalhe significativo que escapa à tentativa de reconstrução de si mesmo através da escrita é o juízo moral sobre suas ações e, principalmente, sobre suas omissões, ou seja, aquelas correções que poderiam ser realizadas a cada edição. Essa é a ausência fundamental. Bento Santiago revê sua desventurada história/tragédia pessoal como uma sucessão de eventos que parecem independentes de si mesmo.

Deus, sua mãe, José Dias, Capitu e Escobar são os principais responsáveis pelos acontecimentos de sua vida, sendo que Capitu é o centro em torno do qual tudo o mais gravita, inclusive Bentinho e sua imaginação.

A seqüência de capítulos mencionada anteriormente exemplifica bem o esquema que será desenvolvido durante o romance sobre a peculiar tibieza de Bentinho: primeiro, exalta a atitude dissimulada de Capitu e afirma "Você tem razão, Capitu, [...]; vamos enganar toda esta 
gente"; em seguida, manifesta um pensamento bastante apropriado ao seu perfil, sobre a necessidade de cumprir com as obrigações "por mais vontade que tenha de as infringir; deslavadamente"; depois, passa para a imaginação da solução simples e rápida, apesar de pecaminosa, de que "Mamãe defunta, acaba o seminário".

A mordaz ironia que perpassa essas linhas é que o personagem-autor afirma que confessará tudo o que "importar" a sua história, tudo o que for "conveniente" à construção ou reconstrução de si mesmo. Ora, se existe uma só voz narrativa, de um personagem-autor que desconfia da própria capacidade de rememoração, pois confessa ter prestado pouca atenção aos fatos vividos e que se coloca à margem de sua própria vida, o verdadeiro protagonista deste romance é o destino, que conspira sob todas as formas para a infelicidade de Bento Santiago. Porque o destino é a desculpa conveniente de uma pessoa omissa ou de um livro omisso, como diria Dom Casmurro.

A incapacidade de Bento-Casmurro para assumir as responsabilidades de seu pertencimento social são deste modo apresentadas por Haberly:

\begin{abstract}
No caso da família Santiago, o dilema é que Bento, filho único e aliás o nosso narrador, é totalmente inadequado às responsabilidades que acompanham a posição social a ser herdada por ele; é incapaz de tomar decisões, facilmente dominado pelos outros, sempre se deixando levar, distraído pelos acontecimentos, nunca se esforçando para os controlar. [...] O casamento [com Capitu] é apenas o primeiro passo à salvação; Bento ainda tem que cumprir a função essencial do patriarca, gerando a descendência que assegurará a perpetuação da família e que encarnará a fusão social. (HABERLY, 2005, p.58)
\end{abstract}

As questões sobre a arte fina de Capitu, sobre a memória pouco confiável, sobre sua impressionabilidade com o grande poder de sua imaginação, integram-se a sua fragilidade moral evocada em pontos esparsos no texto nos quais Bento manifesta sentimentos de inferioridade.

Em relação a Capitu, quando afirma: "Capitu era mais mulher do que eu era homem" (XXXI); ou como na segunda vez que sente ciúmes exagerados por causa de um rapaz "firme na sela", que olhou para Capitu na janela (LXXIII), pois montar à cavalo era costume importante naquele tempo e Bento-Casmurro declara, logo no início da narrativa, que só aprendeu equitação "mais tarde, menos por gosto que por vergonha de dizer que não sabia montar" (VI). E ainda quando confessa-se tomado pela inveja do comportamento da namorada ao indagar: "Como era possível que Capitu se governasse tão facilmente e eu não?" (LXXXIII)

Os outros momentos significativos de reflexão sobre sentimentos de inferioridade em relação a Escobar referem-se à grande capacidade mental deste para a matemática (XCIV), pois, conforme avaliava, "eu não era capaz de resolver de momento um problema filosófico ou lingüístico, ao passo que ele podia somar, em três minutos, quaisquer quantias." E do misto de admiração e desejo que sentiu ao tocar os braços de Escobar "como se fossem os de Sancha" 
quando confessa: "achei-os mais grossos e fortes que os meus, e tive-lhes inveja; acresce que sabiam nadar" (CXVIII).

Tais impressões constrastantes com sua auto-imagem em comparação aos comportamentos e habilidades encontrados nos outros revelam as íntimas fragilidades que Bento Santiago carregava consigo e que mesmo a privilegiada posição social não lograva apagar, apenas camuflava. Mas de todas as constatações de inferioridade, nenhuma foi mais contundente do que a autocomiseração expressa na frase: "de tal ou qual simpatia ao rato que acho em mim" (CXI).

Se o romance de Alexandre Dumas, $O$ conde de Monte Cristo foi considerado pelos críticos como um tratado sobre a vingança, Dom Casmurro, de Machado de Assis, é um tratado sobre a vitimização. Bento Santiago é a grande vítima do seu destino, do seu egoísmo e da sua fraqueza moral.

Se há um gesto de grandiosidade na narrativa de Bento-Casmurro é a sua capacidade de prestigitação (e é aí que se revela o gênio narrativo de Machado de Assis), pois é a transferência do julgamento severo de suas atitudes e omissões concretas, a um imaginado comportamento reprovável de Capitu e Escobar, que produz a grande cortina de fumaça para encobrir seus atos indignos, disfarçar os pensamentos indecorosos e obscurecer os sentimentos mesquinhos que acompanham o percurso vivido e narrado por Bento Santiago.

Bento admite que sua memória não é boa, que não guarda detalhes, mas reconhece que sua imaginação sempre fora fértil, abundante. De fato, sua memória não o ajudou a construir um juízo simples sobre uma questão que sua imaginação encarregou-se de ampliar: se Escobar fosse o pai de seu filho, como seria possível supor que sugerisse que seus filhos se casassem? E Capitu não rejeitaria tal proposição desde o início? (CVIII)

A rapidez com que Bento se desfaz de seus próprios deslizes é contrastante com a rigidez com que julga os atos alheios. A pouca importância que dedica ao empenho do amigo no início de sua carreira "que interveio com um advogado célebre para que [o] admitisse à sua banca" (CIV) em comparação aos intensos louvores das poucas "boas ações" que praticou quase sempre por acaso - são as verdadeiras dissimulações do personagem-autor.

A tragicidade da vida de Bento Santiago não está na suposta traição da mulher com o seu melhor amigo, mas na própria incapacidade de refletir sobre a ausência de suas conquistas pessoais. Bento não foi enganado, ele enganou-se. Bento ganhou a vida, mas perdeu a batalha!

Bento capitulou porque não foi capaz de responsabilizar-se pelas escolhas.

Bento foi para o seminário para cumprir a promessa de sua mãe e de lá saiu graças a idéia de Escobar de transferir a promessa a um substituto. Bento casou-se com Capitu porque 
ela o escolheu, porque ela decidiu esperá-lo e fez-se agradável aos olhos de D. Glória, mesmo pertencendo a um estrato social inferior. Bento conseguiu algum êxito como advogado pela boa vontade de Escobar. De resto, sua vida já estava assegurada desde o princípio pela privilegiada posição social e por ser herdeiro único de família abastada.

Mas Bento fracassa ainda na transmissão do legado, pois, além de não possuir descendentes, seu amargo espólio é a detração da memória de seus afetos pela incapacidade de reconhecer seus erros.

A derradeira ironia presente neste texto é que ao recapitular certos acontecimentos de sua vida Bento-Casmurro faz exatamente o contrário do que afirma: "Tenho-me feito esquecer" (CXLIV). Ainda aqui seus pensamentos não correspondem aos atos, afinal, uma pessoa que quer ser esquecida não torna pública sua história.

\section{Referências}

CHALHOUB, Sidney. Diálogos Políticos em Machado de Assis. In: CHALHOUB, Sidney e PEREIRA, Leonardo Afonso de Miranda (orgs.). A História contada: capítulos de história social da literatura no Brasil. Rio de Janeiro: Nova Fronteira, 1998, p.95-122.

GIANNETTI, Eduardo. Um mergulho em Dom Casmurro. Folha de São Paulo. Caderno Mais!. São Paulo, 27 de jan. 2008. Disponível em: http://www1.folha.uol.com.br/fsp/mais/inde27012008.htm. Acesso em 17 fev 2008.

HABERLY, David T. Dom Casmurro e o romance do adultério feminino. In: SARAIVA, Juracy Assmann. Nos labirintos de Dom Casmurro: ensaios críticos. Porto Alegre: EDIPUCRS, 2005, p.41-60.

MACEDO, Helder. Machado de Assis: entre o lusco e o fusco. In: SARAIVA, Juracy Assmann. Nos labirintos de Dom Casmurro: ensaios críticos. Porto Alegre: EDIPUCRS, 2005, p.83-108.

MACHADO DE ASSIS. A Semana (1895-1900). $3^{\circ}$ vol. Rio de Janeiro: W. M. Jackson, 1944.

MACHADO DE ASSIS. Dom Casmurro. São Paulo: Círculo do Livro, 1987.

MACHADO DE ASSIS. Memórias Póstumas de Brás Cubas. Rio de Janeiro: W. M. Jackson, 1946.

MERQUIOR, José Guilherme. Machado em Perspectiva. Conferência pronunciada no "I Encontro de professores de literatura Brasileira - Machado de Assis: Texto e Contexto", realizado na Faculdade de Letras da UFRJ, em 1989. In: SECCHIN, Antonio Carlos et alii. Machado de Assis - Uma revisão. Rio de Janeiro: In-Fólio Produção Editorial, 1998. 
Disponível em: http://www.olivro.com/machado/notes/Machado_critica.html\#A_01. Acesso em 17 fev 2008.

OS IMORTAIS DA LITERATURA UNIVERSAL Vol. 1. Machado de Assis. São Paulo: Abril Cultural, 1971, p.181-196. 